\title{
p16/INK4a gene methylation is a frequent finding in pulmonary MALT lymphomas at diagnosis
}

\author{
Hisashi Takino ${ }^{1}$, Mitsukuni Okabe ${ }^{1}$, Chunmei Li $^{1}$, Koichi Ohshima ${ }^{2}$, Tadashi Yoshino ${ }^{3}$, \\ Shigeo Nakamura ${ }^{4}$, Ryuzo Ueda ${ }^{5}$, Tadaaki Eimoto ${ }^{1}$ and Hiroshi Inagaki ${ }^{1 *}$ \\ ${ }^{1}$ Department of Pathology, Nagoya City University Graduate School of Medical Sciences, Nagoya, Japan; \\ ${ }^{2}$ Department of Pathology, Fukuoka University Medical School, Fukuoka, Japan; ${ }^{3}$ Department of Pathology, \\ Okayama University Medical School, Okayama, Japan; ${ }^{4}$ Pathology and Molecular Diagnosis, Aichi Cancer \\ Center Hospital, Nagoya, Japan and ${ }^{5}$ Department of Internal Medicine and Molecular Science, Nagoya City \\ University Graduate School of Medical Sciences, Nagoya, Japan
}

\begin{abstract}
p16/INK4a gene alterations have been associated with tumor progression in lymphoid malignancies. However, their significance in mucosa-associated lymphoid tissue (MALT) lymphoma is unclear. We investigated p16 gene methylation and mutation in a large series of untreated cases of pulmonary MALT lymphoma and diffuse large B-cell lymphoma (DLBL), and correlated p16 gene alterations with a MALT lymphoma-specific API2MALT1 fusion and the clinicopathologic features of MALT Iymphoma. The API2-MALT1 fusion was detected by multiplex reverse transcription polymerase chain reaction in 25/60 (42\%) cases of MALT lymphoma, but none of 11 DLBLs. Methylation-sensitive single-strand conformation analysis showed that $p 16$ gene methylation was frequently detected in $36 / 60(60 \%)$ cases of MALT Iymphoma. The gene was similarly methylated in DLBL cases $(6 / 11,55 \%)$. A p16 gene mutation was found in one (p16 gene-methylation) of 44 MALT lymphomas and in none of six diffuse large B-cell lymphomas. Statistical analysis showed that the $p 16$ gene methylation status did not correlate with API2-MALT1 fusion or any of the clinicopathologic factors including serum LDH, clinical stage, and increased large cells. These findings suggest that p16 methylation is not associated with tumor progression, but may be an early event in MALT lymphomagenesis that might be maintained through the progression of the tumor.
\end{abstract}

Modern Pathology (2005) 18, 1187-1192. doi:10.1038/modpathol.3800400; published online 8 April 2005

Keywords: API2-MALT1 fusion; gene methylation; lung; MALT lymphoma; P16/INK4a gene

Extranodal marginal zone B-cell lymphoma of mucosa-associated lymphoid tissue (MALT) runs an indolent clinical course, involves extranodal sites, and exhibits a wide spectrum of histologic features consisting of centrocyte-like cells, lymphoepithelial lesions, and follicular colonization. Pre-existing chronic inflammation, for example, Helicobacter pylori gastritis, Hashimoto's thyroiditis, or Sjogren's syndrome, is considered to be important in the development of MALT lymphoma. Progression to diffuse large B-cell lymphoma (DLBL) may occur in some cases. ${ }^{1}$ An API2-MALT1 gene fusion was cloned from a recurring chromosomal

${ }^{*}$ Correspondence: Dr H Inagaki, MD, Department of Pathology, Nagoya City University Graduate School of Medical Sciences, Kawasumi, Mizuho-ku, Nagoya 467-8601, Japan.

E-mail: hinagaki@med.nagoya-cu.ac.jp

Received 12 November 2004; revised 20 January 2005; accepted 23 January 2005; published online 8 April 2005 translocation of $\mathrm{t}(11 ; 18)(\mathrm{q} 21 ; \mathrm{q} 21) .^{2,3}$ Since this fusion is often the sole gene abnormality found in MALT lymphoma and has not been found in other types of lymphoma, API2-MALT1 fusion has been considered as a specific MALT lymphoma-causing alteration. ${ }^{4-6}$ API2 is a member of the IAP (inhibitor of apoptosis) gene family, and is essential for the suppression of apoptosis. ${ }^{7}$ MALT1 is identical to a novel caspase-like protein termed paracaspase, ${ }^{8}$ although its biologic function remains unclear. It has been suggested that API2-MALT1 fusion transcripts lead to an increased inhibition of apoptosis and thereby help MALT lymphoma cells to survive. ${ }^{9}$

Cell cycle progression is regulated by complexes formed between cyclins and cyclin-dependent kinases (CDKs). CDK4 and CDK6 bind to D-type cyclins in the G1 phase of the cell cycle and control G1/S transition through the phosphorylation of retinoblastoma protein. The activity of cyclinDCDK4/6 complexes is subjected to additional levels 
of regulation, including the association with CDK inhibitors. ${ }^{10}$ The $p 16 / I N K 4 a$ gene, mapped to 9q21, encodes for nuclear protein that can block cell cycle progression by effectively inhibiting the kinase activity of CDK4/6, thereby exerting a negative control on cell proliferation. $p 16$ gene has been considered as a tumor-suppressor gene, and among CDK inhibitors, only $p 16$ gene is frequently silenced in a variety of tumors by epigenetic or genetic abnormalities including promoter $\mathrm{CpG}$ methylation and less frequently, allelic loss and gene mutation. ${ }^{10,11}$ In lymphoid malignancies, $p 16$ gene silencing, mainly induced by gene methylation, is frequently found in Hodgkin and non-Hodgkin lymphomas, ${ }^{12-14}$ and has been associated with tumor progression. ${ }^{15-19}$ However, it has also been suggested that the methylation of this gene is one of the early events in the development of lymphoid malignancies. ${ }^{20-22}$

MALT lymphoma constitutes more than $80 \%$ of all primary lung lymphomas. ${ }^{23}$ It should be noted that the involvement of API2-MALT1 fusion is particularly high (up to half of all cases) in pulmonary MALT lymphoma compared with MALT lymphomas at other sites, ${ }^{24}$ and may define a distinctive clinicopathologic subgroup of pulmonary MALT lymphomas. ${ }^{25}$ Therefore, pulmonary MALT lymphoma is a good model for study of lymphomagenesis. Like other lymphoid malignancies, the p16 gene silencing has been associated with tumor progression in MALT lymphoma. ${ }^{16}$ However, recent studies showed frequent $p 16$ gene methylation in gastric MALT lymphomas at diagnosis, suggesting that it might be an early event. ${ }^{26,27}$ To clarify lymphomagenetic and clinicopathologic significances of $p 16$ gene alterations, we investigated the promoter hypermethylation and sequence mutation of this gene in a large series of pulmonary MALT lymphomas, and correlated these changes with API2-MALT1 fusion.

\section{Materials and methods}

\section{Case Selection}

Specimens of MALT lymphoma $(n=60)$ and diffuse large B-cell lymphoma $(n=11)$ obtained at the initial presentation of the patients were fixed in formalin, and embedded in paraffin. The diagnosis of MALT lymphoma was made according to the criteria of the World Health Organization classification. ${ }^{1}$ All of the cases were within the morphological boundaries of MALT lymphoma, and exhibited the following immunophenotype: $\mathrm{CD} 20+, \mathrm{CD} 79 \mathrm{a}+$, CD3-, CD45RO-, CD5-, CD10-, CD23-, and cyclin D1-. A precise microscopic observation revealed that 46 of 60 cases were 'typical' in histology. ${ }^{1,25}$ However, seven cases showed an increased number of large cells $(5 \%<$ large cells $<10 \%$, without solid or sheet-like proliferations), and seven cases exhibited marked plasmacytoid differentiation (plasmacytoid tumor cells >90\%). The mean age of MALT lymphoma patients was 62.1 years with a range of 31-94 years. The male/female ratio was $22 / 38$. The mean age of DLBL patients was 61 years with a range of 37-84 years. The male/ female ratio was $7 / 4$. Some of the tumors in this series were included in our previous study. ${ }^{25}$

\section{Extraction of Genomic DNA and Total RNA}

On examination of tissue sections under a dissecting microscope, selected areas were retrieved using a serial H\&E section as a guide. Genomic DNA and total RNA were extracted in digestion buffer containing proteinase $\mathrm{K}$ as previously described..$^{25,28}$ For all cases included in this study, monoclonality was confirmed by a polymerase chain reaction (PCR) clonality assay of the immunoglobulin heavy chain gene and/or immunohistochemistry for immunoglobulin light chains as previously described. ${ }^{25}$ We also confirmed that all cases had a sufficient quality of RNA by reverse transcription (RT)-PCR for betaactin mRNA (190 base). ${ }^{28}$ As normal controls, 12 lung and 14 lymph node specimens were used and these were obtained from carcinoma patients during surgery.

\section{Multiplex RT-PCR for the API2-MALT1 Fusion Transcript}

The API2-MALT1 fusion transcript was detected using archival paraffin sections according to the method we previously reported. ${ }^{28}$ All eight variant fusion transcripts that have been reported to date can be detected with this assay (Figure 1a; accession number L49432 for API2 and accession number AF130356 for MALT1). Briefly, total RNA was subjected to first-round multiplex one-tube RTPCR, then to second-round nested multiplex PCRs (three in parallel: second PCR-A, second PCR-B, and second PCR-C). This RT-PCR assay using paraffin tissues is highly efficient and has $94 \%$ of the sensitivity and $100 \%$ of the specificity obtained with RT-PCR using frozen materials. ${ }^{25}$

\section{DNA Bisulfite Modification and Methylation-Specific Single-Strand Conformation Analysis (MS-SSCA)}

Genomic DNA extracted from lymphoma samples and a Raji lymphoma cell line (methylation-positive control) were examined for $p 16$ gene methylation by MS-SSCA. ${ }^{29}$ In brief, DNA was first heated at $98^{\circ} \mathrm{C}$ for $10 \mathrm{~min}$, and then for another $10 \mathrm{~min}$ at $37^{\circ} \mathrm{C}$ with the addition of freshly prepared $3 \mathrm{~N} \mathrm{NaOH}$. After addition of $10 \mathrm{nmol} / \mathrm{l}$ hydroquinone and $4.8 \mathrm{~mol} / \mathrm{l}$ sodium bisulfite, the mixture was incubated at $55^{\circ} \mathrm{C}$ overnight. DNA modification was completed by adding $0.2 \mathrm{~mol} / \mathrm{l} \mathrm{NaOH} / 90 \%$ ethanol. A $194 \mathrm{bp}$ fragment of the $p 16$ gene promoter was amplified by 


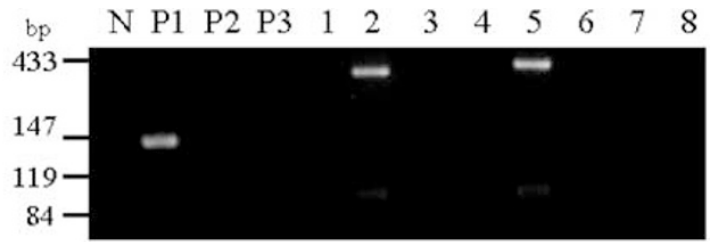

b

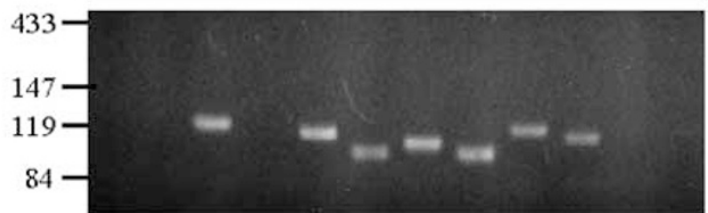

C

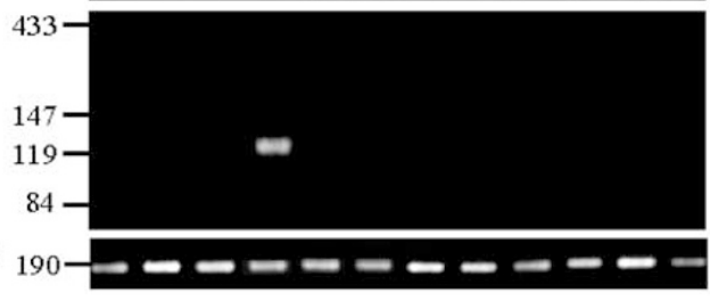

$\beta-$ acti RNA

Figure 1 Detection of the API2-MALT1 fusion transcript by multiplex RT-PCR. (a) Second PCR-A, (b) Second PCR-B, (c) Second PCR-C; N, negative control (normal lymph node); P1, P2, P3, positive controls for Second PCR-A, -B, and -C, respectively; Lanes 1 - 6, pulmonary MALT lymphomas positive for the API2MALT1 fusion transcript; lanes 7 and 8, pulmonary MALT lymphomas negative for the fusion transcript. Note that the fusion transcript was detected in both Second PCR-A and Second PCR-B (lanes 2 and 5). Beta-actin mRNA (190 base pairs) is amplified in all cases.

PCR using the following primers specific to the modified sequences: $5^{\prime}$-GGGGGAGATTTAATTTGG$3^{\prime}$ and $5^{\prime}$-CAACCCCTCCTCTTTCTT-3'. After denaturation, the PCR samples were immediately electrophoresed on a 30\% MDE gel (Cambrex Bio Science Rockland, Rockland, ME, USA) with a constant voltage of $10 \mathrm{~V} / \mathrm{cm}$ for $4 \mathrm{~h}$ at $20^{\circ} \mathrm{C}$. Gels were then stained with a SYBR Green I (Molecular Probes, Eugene, OR, USA), and bands were visualized with UV light.

\section{Mutation Analysis of the p16 Gene by PCR-Single-Strand Conformation Polymorphism (SSCP)}

PCR amplification of the $p 16$ gene was performed using a primer pair for exon 1 (GGGCGGCGGGGAG CAGC and GCTGCAGACCCTCTACCCAC) and two primer pairs for exon 2 (5'-ACCCTGGCTCTGAC CATTCTGT- ${ }^{\prime}$ and $5^{\prime}$-GGCATCGCGCACGTCCAGC$3^{\prime}$ and $5^{\prime}$-GGGCTTCCTGGACACGCTGGT- $3^{\prime}$ and $5^{\prime}-$ GGAAGCTCTCAGGGTACAAATTCTCA- $3^{\prime}$ ). ${ }^{30}$ After denaturation, the PCR products were electrophoresed and separated using a GeneGel Exel 12.5/24 Kit (GenePhor System, Amersham Biosciences, Piscataway, NJ, USA) at two different temperatures, $15^{\circ} \mathrm{C}$ and $5^{\circ} \mathrm{C}$, and the gels were subjected to silver staining. Mutational bands were excised from the gels and reamplified using the same PCR primers.
The amplified DNA was directly sequenced by means of cycle sequencing with dye-labeled terminators (BigDye Terminators, Applied Biosystems, Foster City, CA, USA) and analyzed on an automated DNA sequencer.

\section{Statistical Analysis}

Statistical evaluation of data from two groups was performed using Fischer's exact test and Student's $t$-test. All analyses were two-tailed. A probability value of $P<0.05$ for each test was regarded as statistically significant.

\section{Results}

\section{API2-MALT1 Fusion Transcript}

The multiplex RT-PCR detected API2-MALT1 fusion in $25 / 60(42 \%)$ cases of pulmonary MALT lymphoma. The bands varied in size depending on the breakpoints and primer sets used (Figure 1). The API2 breakpoints were restricted to 1446 (accession number. L49432) in all cases with one exception which had a breakpoint at 1701. In contrast, the MALT1 breakpoint (accession number. L49432) varied with nine cases at 814,10 cases at 1123 , and six cases at 1150. API2-MALT1 fusion transcript was negative for MALT lymphomas with increased large cells (0/7 cases) and DLBLs (0/11).

\section{p16 Gene Methylation Analysis by MS-SSCA}

The $p 16$ gene methylation was detected in 36/60 $(60 \%)$ cases of MALT lymphoma: $32 / 53(60 \%)$ and $4 / 7(57 \%)$ cases of MALT lymphomas without and with an increased component of large cells, respectively (Figure 2). The gene methylation was detected in $6 / 11(55 \%)$ cases of DLBL. Statistically significant difference was not obtained between any two of the above groups. $p 16$ gene methylation was detected in none of 12 normal lung tissues or 14 normal lymph node specimens.

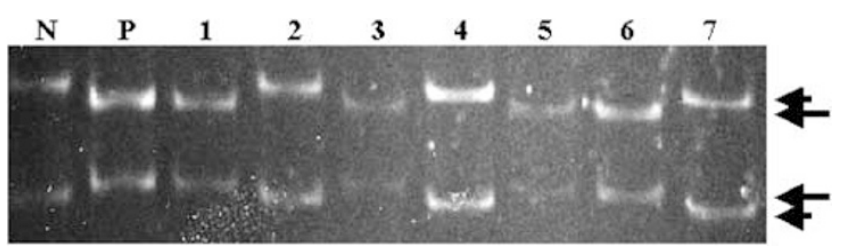

Figure 2 MS-SSCA of $p 16$ gene methylation. N, negative control; $\mathrm{P}$, positive control (Raji lymphoma cell line); lanes 1, 3, 5, and 6, pulmonary MALT lymphomas showing $p 16$ gene methylation; lanes, 2, 4, and 7, pulmonary MALT lymphomas showing no methylation. In comparison with bands of normal controls (short arrows), those of $p 16$ gene methylation cases show a mobility shift (long arrows). 


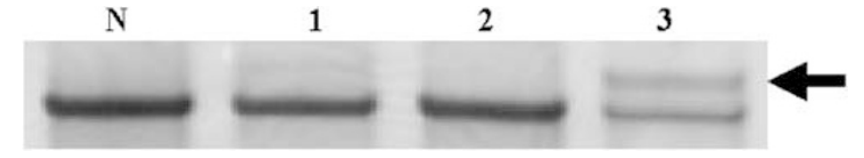

Figure 3 PCR-SSCP of $p 16$ gene mutation. An aberrant SSCP pattern for exon 2 (lane 3 , arrow) resulted in a missense mutation. $\mathrm{N}$, negative control.

\section{p16 Gene Mutation Analysis by PCR-SSCP}

The $p 16$ whole coding region was amplified in 44 cases of MALT lymphoma and eight cases of DLBL. One MALT lymphoma case $(2 \%)$ showed a nucleotide substitution of $\mathrm{G}$ to $\mathrm{A}$ at codon 135 that changed GGG (glycine) to GAG (glutamic acid) (Figure 3). This case showed 'typical' MALT lymphoma histology and $p 16$ gene methylation by MS-SSCA. None of the DLBL cases possessed $p 16$ gene mutation.

\section{Correlation of $p 16$ Gene Methylation with Clinicopathologic Factors and API2-MALT1 Fusion}

Available clinicopathologic factors included age, sex, chief complaints, autoimmune disease, serum LDH, clinical stage, B-symptoms, 'typical' histology, increased large cells, and marked plasmacytoid differentiation. $p 16$ gene methylation correlated with none of these factors, nor did it correlate with API2-MALT1 fusion status (Table 1).

\section{Discussion}

p16/INK4a gene methylation was detected in diagnostic specimens of more than half of the cases of not only MALT lymphoma but also MALT lymphoma with increased large cells and DLBL. The MS-SSCA used in this study is a rapid and specific procedure for detecting gene methylation, especially in paraffin-embedded tissues, and gives fewer false-positive results. ${ }^{29}$ The influence of $p 16$ gene methylation on background non-neoplastic cells is considered to be minimal because no methylation was detected in normal pulmonary tissues in the present and previous studies. ${ }^{31}$ p16 gene mutation was found in one MALT lymphoma case, which involved methylation of the $p 16$ gene. Consequently, gene methylation was a major occurrence among p16 gene alterations in our study, which is in accord with previous reports. ${ }^{10-16}$ Gene deletion is another means of $p 16$ gene silencing, but has been rare in MALT lymphomas. ${ }^{32,33}$ We attempted to detect $p 16$ gene deletions using seven microsatellite markers, ${ }^{16,34}$ however, most of the cases were not amplifiable or informative. We found no evidence of p16 deletion in eight cases (six of MALT lymphoma and two of DLBL) that were suitable for evaluation (unpublished data).

The most important finding of our study is that p16 gene was frequently methylated in pulmonary
Table 1 Correlation of $p 16$ gene methylation with clinicopathologic and molecular factors

\begin{tabular}{|c|c|c|c|}
\hline & & p16 gene & \\
\hline & Methylated $(\mathrm{n}=36)$ & Unmethylated $(\mathrm{n}=24)$ & $\mathrm{P}$ \\
\hline Clinical fact & & & \\
\hline Age & & & \\
\hline Mean & 60.3 & 64.8 & NS \\
\hline$<60$ & 17 & 6 & \\
\hline$>60$ & 19 & 18 & NS \\
\hline Sex & & & \\
\hline Male & 12 & 10 & \\
\hline Female & 24 & 14 & NS \\
\hline Chief compl & ints & & \\
\hline Present & 10 & 5 & \\
\hline Absent & 26 & 19 & NS \\
\hline Autoimmun & disease & & \\
\hline Positive & 3 & 3 & \\
\hline Negative & 33 & 21 & NS \\
\hline$L D H(n=55)$ & & & \\
\hline Elevated & 5 & 1 & \\
\hline Normal & 27 & 22 & NS \\
\hline Stage $(n=55$ & & & \\
\hline I, II & 24 & 21 & \\
\hline III, IV & 8 & 2 & NS \\
\hline B-symptoms & $n=55)$ & & \\
\hline Present & 4 & 2 & \\
\hline Absent & 28 & 21 & NS \\
\hline Histopatholc & jic factors & & \\
\hline Histology & & & \\
\hline ‘Typical’ & 29 & 17 & \\
\hline 'Atypical' & 7 & 7 & NS \\
\hline Increased la & ge cells & & \\
\hline Yes & 4 & 3 & \\
\hline No & 32 & 21 & NS \\
\hline Marked plas & nacytoid differentiatic & & \\
\hline Yes & 3 & 4 & \\
\hline No & 33 & 20 & NS \\
\hline API2-MALT & fusion & & \\
\hline Positive & 15 & 10 & \\
\hline Negative & 21 & 14 & NS \\
\hline
\end{tabular}

NS, not significant.

MALT lymphomas (60\% of the cases) at diagnosis. It was methylated with similar frequencies in MALT lymphomas with increased large cells (57\%) and DLBLs $(55 \%)$, and its gene methylation did not correlate with any of the clinical factors such as serum LDH, stage, and B-symptoms. p16 gene methylation has been considered to be a molecular event associated with the progression of MALT lymphoma to its high-grade counterpart. ${ }^{15-19}$ However, our findings suggest that p16 gene methylation is not associated with the tumor progression but rather may contribute to the 
development of MALT lymphoma. Although the gene methylation was detected in DLBL as frequently as MALT lymphoma in our study, this observation may be explained by maintenance of the early phase gene abnormality through the history of the tumor. The hypothesis that $p 16$ gene methylation is an early event in MALT lymphomagenesis may be supported by the recent findings that $p 16$ gene repression is crucial for immortalization of several human cells ${ }^{35,36}$ and by the frequent $p 16$ gene methylation found in monoclonal gammopathy of undetermined significance, in the plaque phase of mycosis fungoides, and in other premalignant lesions. ${ }^{20-22,37}$

Several MALT lymphoma-specific or -associated gene alterations have been reported, such as translocations between the immunoglobulin heavy chain gene and BCL10 gene or MALT1 gene, trisomy 3 , and trisomy 18 , as well as API2-MALT1 fusion. ${ }^{38}$ These seem to be mutually exclusive, and constitute up to $80 \%$ of the pulmonary MALT lymphoma cases. ${ }^{38}$ A recent study of an API2-MALT1 transgenic mouse model showed that the expression of the fusion protein did not induce spontaneous development of MALT lymphomas, ${ }^{39}$ suggesting that the fusion gene alone would not be sufficient for MALT lymphoma development. This would be also the case for other gene alterations. In this study, while p16 gene methylation was not directly associated with API2-MALT1 fusion, we speculate that it is important as one of the early events of MALT lymphomagenesis and plays a role in tumor development in cooperation with several MALT lymphoma-specific or -associated gene alterations. To date, several studies have shown that methylation-associated silencing of tumor suppressor genes is one of the cancer-predisposing hits described in Knudson's two hit theory. ${ }^{11}$

Unlike genetic alterations, changes in DNA methylation are potentially reversible. This possibility has attracted considerable attention from a therapeutics standpoint. Nucleoside-analogue inhibitors of DNA methyltransferases, such as 5-aza-2'deoxycytidine, are able to demethylate DNA and restore silenced gene expression. ${ }^{40,41}$ Recently, some non-nucleoside inhibitors of DNA methyltransferases have also been reported as promising candidate agents for future cancer therapies based on epigenetics, including procainamide and procaine. ${ }^{42}$ The clinical and therapeutic significance of these agents in pulmonary MALT lymphoma should be investigated.

\section{Acknowledgements}

This work was supported in part by a Grant-in-Aid from the Ministry of Education, Science, Sports, and Culture of Japan and a Grant-in-Aid from the Foundation for Promotion of Cancer Research for $\mathrm{H}$ Inagaki.

\section{References}

1 Isaacson PG, Berger F, Mueller-Hermelink HK, et al. Extranodal marginal zone B-cell lymphoma of mucosa-associated lymphoid tissue (MALT lymphoma) In: Jaffe E, Harris NL, Stein H, Vardiman JW (eds). Tumours of Haematopoietic and Lymphoid Tissues. World Health Organization Classification of Tumors, Pathology and Genetics. IARC Press: Lyon, 2001, pp 157-160.

2 Akagi T, Motegi M, Tamura A, et al. A novel gene, MALT1 at 18q21, is involved in $\mathrm{t}(11 ; 18)(\mathrm{q} 21 ; \mathrm{q} 21)$ found in low-grade B-cell lymphoma of mucosaassociated lymphoid tissue. Oncogene 1999;18: 5785-5794.

3 Dierlamm J, Baens M, Wlodarska I, et al. The apoptosis inhibitor gene API2 and a novel $18 \mathrm{q}$ gene, MLT, are recurrently rearranged in the $t(11 ; 18)(q 21 ; q 21)$ associated with mucosa-associated lymphoid tissue lymphomas. Blood 1999;93:3601-3609.

4 Baens M, Maes B, Steyls A, et al. The product of the $\mathrm{t}(11 ; 18)$, an API2-MLT fusion, marks nearly half of gastric MALT type lymphomas without large cell proliferation. Am J Pathol 2000;156:1433-1439.

5 Motegi M, Yonezumi M, Suzuki H, et al. API2-MALT1 chimeric transcripts involved in mucosa-associated lymphoid tissue type lymphoma predict heterogeneous products. Am J Pathol 2000;156:807-812.

6 Remstein ED, James CD, Kurtin PJ. Incidence and subtype specificity of API2-MALT1 fusion translocations in extranodal, nodal, and splenic marginal zone lymphomas. Am J Pathol 2000;156:1183-1188.

7 Roy N, Deveraux QL, Takahashi R, et al. The c-IAP-1 and c-IAP-2 proteins are direct inhibitors of specific caspases. EMBO J 1997;16:6914-6925.

8 Uren AG, O’Rourke K, Aravind LA, et al. Identification of paracaspases and metacaspases: two ancient families of caspase-like proteins, one of which plays a key role in MALT lymphoma. Mol Cell 2000;6: 961-967.

9 Hosokawa Y, Suzuki H, Suzuki Y, et al. Antiapoptotic function of apoptosis inhibitor 2-MALT1 fusion protein involved in $\mathrm{t}(11 ; 18)(\mathrm{q} 21 ; \mathrm{q} 21)$ mucosa-associated lymphoid tissue lymphoma. Cancer Res 2004;64: 3452-3457.

10 Drexler HG. Review of alterations of the cyclindependent kinase inhibitor INK4 family genes p15, p16, p18 and p19 in human leukemia-lymphoma cells. Leukemia 1998;12:845-859.

11 Garinis GA, Patrinos GP, Spanakis NE, et al. DNA hypermethylation: when tumour suppressor genes go silent. Hum Genet 2002;111:115-127.

12 Martinez-Delgado B, Fernandez-Piqueras J, Garcia MJ, et al. Hypermethylation of a $5^{\prime} \mathrm{CpG}$ island of p16 is a frequent event in non-Hodgkin's lymphoma. Leukemia 1997;11:425-428.

13 Baur AS, Shaw P, Burri N, et al. Frequent methylation silencing of p15(INK4b) (MTS2) and p16(INK4a) (MTS1) in B-cell and T-cell lymphomas. Blood 1999; 94:1773-1781.

14 Garcia JF, Villuendas R, Algara P, et al. Loss of p16 protein expression associated with methylation of the p16INK4A gene is a frequent finding in Hodgkin's disease. Lab Invest 1999;79:1453-1459.

15 Pinyol M, Cobo F, Bea S, et al. J p16(INK4a) gene inactivation by deletions, mutations, and hypermethylation is associated with transformed and aggressive 
variants of non-Hodgkin's lymphomas. Blood 1998; 91:2977-2984.

16 Villuendas R, Sanchez-Beato M, Martinez JC, et al. Loss of p16/INK4A protein expression in non-Hodgkin's lymphomas is a frequent finding associated with tumor progression. Am J Pathol 1998;153:887-897.

17 Nosaka K, Maeda M, Tamiya S, et al. Increasing methylation of the CDKN2A gene is associated with the progression of adult T-cell leukemia. Cancer Res 2000;60:1043-1048.

18 Mateos MV, Garcia-Sanz R, Lopez-Perez R, et al. Methylation is an inactivating mechanism of the p16 gene in multiple myeloma associated with high plasma cell proliferation and short survival. Br J Haematol 2002;118:1034-1040.

19 Navas IC, Algara P, Mateo M, et al. p16(INK4a) is selectively silenced in the tumoral progression of mycosis fungoides. Lab Invest 2002;82:123-132.

20 Gonzalez M, Mateos MV, Garcia-Sanz R, et al. De novo methylation of tumor suppressor gene p16/INK4a is a frequent finding in multiple myeloma patients at diagnosis. Leukemia 2000;14:183-187.

21 Guillerm G, Gyan E, Wolowiec D, et al. p16/INK4a and p15/INK4b gene methylation in plasma cells from monoclonal gammopathy of undetermined significance. Blood 2001;98:244-246.

22 Scarisbrick JJ, Woolford AJ, Calonje E, et al. Frequent abnormalities of the p15 and p16 genes in mycosis fungoides and Sezary syndrome. J Invest Dermatol 2002;118:493-499.

23 Cadranel J, Wislez M, Antoine M. Primary pulmonary lymphoma. Eur Respir J 2002;20:750-762.

24 Ye H, Liu H, Attygalle A, et al. Variable frequencies of $t(11 ; 18)(q 21 ; q 21)$ in MALT lymphomas of different sites: significant association with CagA strains of $\mathrm{H}$. pylori in gastric MALT lymphoma. Blood 2003;102: 1012-1018.

25 Okabe M, Inagaki H, Ohshima K, et al. API2-MALT1 fusion defines a distinctive clinicopathologic subtype in pulmonary extranodal marginal zone B-cell lymphoma of mucosa-associated lymphoid tissue. Am J Pathol 2003;162:1113-1122.

26 Kaneko Y, Sakurai S, Hironaka M, et al. Distinct methylated profiles in Helicobacter pylori dependent and independent gastric MALT lymphomas. Gut 2003; 52:641-646.

27 Huang Q, Ai L, Zhang ZY, et al. Promoter hypermethylation and protein expression of the p16 gene: analysis of 43 cases of B-cell primary gastric lymphomas from China. Mod Pathol 2004;17:416-422.

28 Inagaki H, Okabe M, Seto M, et al. API2-MALT1 fusion transcripts involved in mucosa-associated lymphoid tissue lymphoma: multiplex RT-PCR detection using formalin-fixed paraffin-embedded specimens. Am J Pathol 2001;158:699-706.

29 Bian YS, Yan P, Osterheld MC, et al. Promoter methylation analysis on microdissected paraffin- embedded tissues using bisulfite treatment and PCRSSCP. Biotechniques 2001;30:66-72.

30 Bian YS, Osterheld MC, Fontolliet C, et al. p16 inactivation by methylation of the CDKN2A promoter occurs early during neoplastic progression in Barrett's esophagus. Gastroenterology 2002;122: 1113-1121.

31 Waki T, Tamura G, Tsuchiya T, et al. Promoter methylation status of E-cadherin, hMLH1, and p16 genes in nonneoplastic gastric epithelia. Am J Pathol 2002;161:399-403.

32 Dierlamm J, Stefanova M, Wlodarska I, et al. Analysis of the P53, RB/D13S25, and P16 tumor suppressor genes in marginal zone B-cell lymphoma: an interphase fluorescence in situ hybridization study. Cancer Genet Cytogenet 2000;120:1-5.

33 Neumeister P, Hoefler G, Beham-Schmid C, et al. Deletion analysis of the p16 tumor suppressor gene in gastrointestinal mucosa-associated lymphoid tissue lymphomas. Gastroenterology 1997;112:1871-1875.

34 Herranz M, Urioste M, Santos J, et al. Analysis of the INK4a/ARF locus in non-Hodgkin's lymphomas using two new internal microsatellite markers. Leukemia 1999;13:808-810.

35 Kiyono T, Foster SA, Koop JI, et al. Both Rb/p16INK4a inactivation and telomerase activity are required to immortalize human epithelial cells. Nature 1998;396: 84-88.

36 Farwell DG, Shera KA, Koop JI, et al. Genetic and epigenetic changes in human epithelial cells immortalized by telomerase. Am J Pathol 2000;156: 1537-1547.

37 Belinsky SA, Nikula KJ, Palmisano WA, et al. Aberrant methylation of p16(INK4a) is an early event in lung cancer and a potential biomarker for early diagnosis. Proc Natl Acad Sci USA 1998;95:11891-11896.

38 Streubel B, Simonitsch-Klupp I, Mullauer L, et al. Variable frequencies of MALT lymphoma-associated genetic aberrations in MALT lymphomas of different sites. Leukemia 2004;18:1722-1726.

39 Sagaert X, De Wolf-Peeters C, Marynen P, et al. API2MLT transgenic mice: a model for the pathogenesis of MALT lymphomas? [Abstract \#2161]. Blood 2003; 102:586a.

40 Cameron EE, Bachman KE, Myohanen S, et al. Synergy of demethylation and histone deacetylase inhibition in the re-expression of genes silenced in cancer. Nat Genet 1999;21:103-107.

41 Issa JP, Garcia-Manero G, Giles FJ, et al. Phase 1 study of low-dose prolonged exposure schedules of the hypomethylating agent 5-aza-2'-deoxycytidine (decitabine) in hematopoietic malignancies. Blood 2004;103: 1635-1640.

42 Villar-Garea A, Fraga MF, Espada J, et al. Procaine is a DNA-demethylating agent with growth-inhibitory effects in human cancer cells. Cancer Res 2003;63: 4984-4989. 